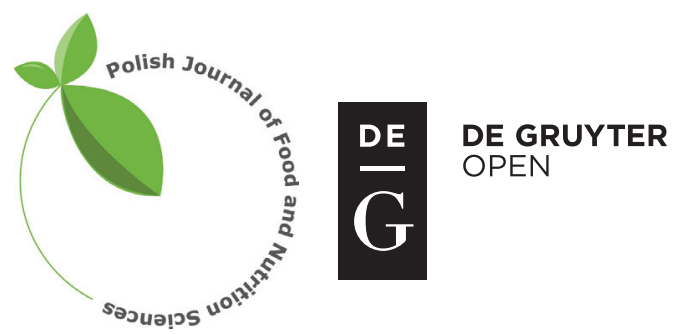

Pol. J. Food Nutr. Sci., 2018, Vol. 68, No. 2, pp. 133-140 DOI: $10.1515 /$ pjfns-2017-0015 http://journal.pan.olsztyn.pl

Original research article

Section: Analytical Section

\title{
Dietary Fiber Extraction from Defatted Corn Hull by Hot-Compressed Water
}

\author{
Li Wang', Hua-Min Liu ${ }^{2,1, *}$, Ai-Jun Xie ${ }^{2}$, Chun-Yan Zhu', Guang-Yong Qin ${ }^{1}$ \\ ${ }^{1}$ College of Physics Engineering, Zhengzhou University, Zhengzhou, Henan 450001, China \\ 2 Province Key Laboratory of Transformation and Utilization of Cereal Resource, \\ Henan University of Technology, Zhengzhou, Henan 450001, China
}

Key words: corn hull, hot-compressed-water extraction, soluble dietary fiber, sugar composition, FT-IR

Corn hulls were abundant and inexpensive byproducts of the corn dry or wet milling processes, but most of them were discarded as agro-wastes. The aim of this study was to extract the dietary fiber by hot-compressed water (HCW) from defatted corn hull and to determine the chemical properties. Results showed that temperature and time played critical roles in extraction efficiency; the maximal yield of dietary fiber A (DFA) extracted by HCW reached $33.0 \%$ at $150^{\circ} \mathrm{C}$ for $60 \mathrm{~min}$. The yield of dietary fiber B (DFB) increased from $2.0 \%$ to $56.9 \%$ as the temperature increased from 110 to $180^{\circ} \mathrm{C}$, while the yield of solid residue (SR) decreased from $88.7 \%$ to $27.7 \%$. Fourier transform infrared spectroscopy (FT-IR) results demonstrated that C-H, $\mathrm{O}-\mathrm{H}, \mathrm{C}=\mathrm{O}, \mathrm{COO}$ - occurred in the DFA, SR and DFB. The dietary fiber polysaccharides consisted of arabinose, galactose, glucose, xylose and uronic acid.

\section{INTRODUCTION}

Corn hulls were abundant and inexpensive by-products of the corn dry milling and wet milling processes, which contain a large percentage of valuable hemicelluloses [Yadav et al., 2016]. Corn hull is the main ingredient of corn gluten feed, which is a low-value feed for cattle [Kálmán et al., 2006]. For economic reasons it may be particularly interesting to apply by-products from the branches of the food industry, which are sources of components of high nutritive value [Makowska et al., 2013]. With the increase of corn productions for the corn starch and ethanol industry, the abundant production of corn hull could also be utilized for various other processes in food industry.

Corn hull contains hemicelluloses (30\%-50\%), cellulose (approximately 20\%), phenolic acids (approximately 4\%, mainly ferulic and diferulic acid), starch (9-23\%), proteins (10-13\%), lipids (2-3\%) and ash (2\%) [Saulnier et al., 1995a; Dhingra et al., 2012; Gáspár et al., 2005, 2007]. There are more abundant total fibers in corn hull [Chanliaud et al., 1995]. Therefore, corn hull is a good source for dietary fiber. Dietary supplements are also more and more frequently used for body mass reduction. These kinds of products contain plant materials and microelements which could increase the metabolism and cause the reduction of fat tissue [ et al., 2012]. It is deduced that dietary fiber maintains several physicochemical functions (such as water binding and alteration of viscosity), which in turn contributes to physiological

\footnotetext{
* Corresponding Author: Tel.: +86-0371-67789937; Fax: +86-037167789937; E-mail: liuhuamin5108@163.com
}

attenuations such as cholesterol and fat binding, decreasing in blood glucose level, preventing constipation and facilitating good colonic health [Foschia et al., 2013]. In addition, dietary fiber consists of insoluble dietary fiber (IDF) and soluble dietary fiber (SDF). IDF is composed of cellulose, lignin and insoluble part of hemicelluloses. SDF comprises pectin, gums, mucilages and soluble part of hemicelluloses [Dhingra et al., 2012]. Cellulose is a polymer of glucose, however, unlike starch, the specific structure of cellulose favors the ordering of the polymer chains into tightly packed, highly crystalline structures, which are water-insoluble and difficult to de-polymerize [Gáspár et al., 2007]. The other carbohydrate component in corn fiber is mostly hemicellulose, which is a well-branched polymer of xylose substituted with galactose, mannose, arabinose, and glucose [Peng et al., 2012; Merali et al., 2015]. The content of water-soluble hemicelluloses in corn fiber was important to estimate the effect of corn fiber supplementation on the inhibition of harmful metabolite production in the gut, because harmful enzyme activities and metabolites were decreased by both corn fiber and hemicelluloses supplementation [Sugawara et al., 1989; 1990, 1991a, b].

Water is an effective and "green" solvent for the direct extraction of water-soluble dietary fiber. Subcritical water, also called $\mathrm{HCW}$, is water that maintains its liquid state in the temperature range of $100-374^{\circ} \mathrm{C}$ under pressurized conditions [Wang et al., 2014]. Its unique properties include a lower relative dielectric constant and a higher ion product compared with ambient water. The other advantage of the process is that it does not require a drying process for raw material. Because the water in raw material is used as a solvent as well as a reac- 
tant in the process, and the drying process, which is required a high energy cost, is not required for the extraction of wet corn hull [Liu et al., 2012]. Therefore, extraction of dietary fiber from corn hull by HCW without acid or alkaline addition would bring about the effective utilization of defatted corn hull, most of which is discarded as agro-waste, using an environment-friendly and safe extractant which has been gaining researchers' attention due to its non-toxic, non-flammable, non-explosive properties [Rogalinski et al., 2008; Carr et al., 2010; Liu et al., 2016]. Also, by understanding chemical properties of dietary fiber, one can increase waste reuse in food applications and aid in developing food products with high consumer acceptance.

The object of this study was to demonstrate the potential of the HCW as an extractant to recover beneficial products from defatted corn hull and to study the chemical properties. The extraction products were segregated into two water-soluble fractions (dietary fiber A (DFA) and dietary fiber B $(\mathrm{DFB})$ ), and a solid residue (SR). The effects of the extraction conditions (temperature, time and corn hull to water ratio) on product yields were investigated. The chemical properties of the dietary fibers were characterized by monosaccharide composition analysis and FT-IR. The DFAs were characterized by protein, starch and total sugar analysis to help understand the mechanism of the hydrothermal extraction of corn hulls.

\section{MATERIALS AND METHODS}

\section{Materials}

Corn hull was provided by Qingdao Yu Tai Feng trade LTD (Shandong, China). The air-dried sample was ground and sieved to obtain a 20-40 mesh fraction. This fraction was subjected to extraction with subcritical butane in a flow circulatory extraction apparatus (CBE-5L, Yalinjie, Anyang, China). During defatting process, the ratio of the sample to solvent was $1: 20 \mathrm{~g} / \mathrm{mL}$, and the defatting temperature was controlled with a water circulator $\left(45^{\circ} \mathrm{C}\right)$. The sample was extracted three times to ensure the maximum removal of lipids. At the end of the process, the liposoluble substances reached the separator and, after the solvent was removed by evaporation, the defatted sample was gathered. The defatted corn hull was dried at $105^{\circ} \mathrm{C}$ for $24 \mathrm{~h}$ and kept in desiccators at room temperature before used. The composition analysis of defatted corn hull was performed according to Liu et al. [2013]. The total dietary fiber was determined according to AOAC method 985.29 [2005] using an enzymatic-gravimetric method and the total sugar was analyzed by phenol sulfuric acid [Nielsen, 2010]. The ash of defatted corn hull was determined by incineration at $650^{\circ} \mathrm{C}$ for $6 \mathrm{~h}$. Results showed that the sample contained water $(1.05 \%)$, protein $(10.23 \%)$, starch $(0.65 \%)$, total dietary fiber $(80.30 \%)$, lipids $(0.86 \%)$, and ash $(0.95 \%)$ (on a dry basis).

\section{Sequential extraction of corn hull dietary fiber}

In a typical run, 10-g defatted corn hull sample and water were mixed in a $350 \mathrm{~mL}$ Synthware ${ }^{\circledR}$ pressure glass vial (Beijing Synthware Glass, Inc, China) and heated in oil bath by a magnetic heating stirrer (IKA, Germany) at a corn hull to water ratio of 1:20 g/mL. Agitation was set at $500 \mathrm{rpm}$ and kept constant for all experiments. The reactor was heated up to the setting temperature and the temperature was maintained constant at the setting temperature for the desired holding time. After the reaction completed, the reactor was cooled down to room temperature by air. When the reactor was opened, the reaction mixture was removed for separation. The procedure for the separation is shown in Figure 1. The aqueous solution was filtered to separate the water-soluble fraction. The filtrate was concentrated to about $30 \mathrm{~mL}$ on a rotary evaporator (RE-52AA, Shanghai Yarong Biochemistry Instrument Factory, Shanghai, China) under reduced pressure at bath temperature of $45^{\circ} \mathrm{C}$. The water-soluble fraction was then recovered by precipitation of the concentrated water extracts in 4 volumes of $95 \%$ ethanol. The precipitation was recovered by filtration, washed with $70 \%$ ethanol and dried at $40^{\circ} \mathrm{C}$, and labeled as DFA. The filtrate was concentrated under reduced pressure at $45^{\circ} \mathrm{C}$ and dried at $40^{\circ} \mathrm{C}$, and labeled as DFB. The water-insoluble fraction was also dried at $40^{\circ} \mathrm{C}$ then weighed and called SR.

All the product yields were calculated on a dry-ash-free basis and each experiment was performed in duplicate. The differences between the results of two tests were below $5 \%$ of the values.

\section{FT-IR}

The FT-IR spectrum of polysaccharide was recorded with a FT-IR spectrometer (Nicolet iN10, Thermo Nicolet Corporation, Madison, WI, USA) equipped with a liquid nitrogen-cooled MCT detector. The experiments were carried out in the range of $4000-400 \mathrm{~cm}^{-1}$ with a resolution of $8 \mathrm{~cm}^{-1}$ and total of 32 scans for each sample.

\section{Determination of polysaccharide composition}

The monosaccharide compositions of DFA, SR and DFB polysaccharides were analyzed by high performance anion exchange chromatography (HPAEC) coupled with pulsed amperometric detector after acid hydrolysis $\left(72 \% \mathrm{H}_{2} \mathrm{SO}_{4}\right.$

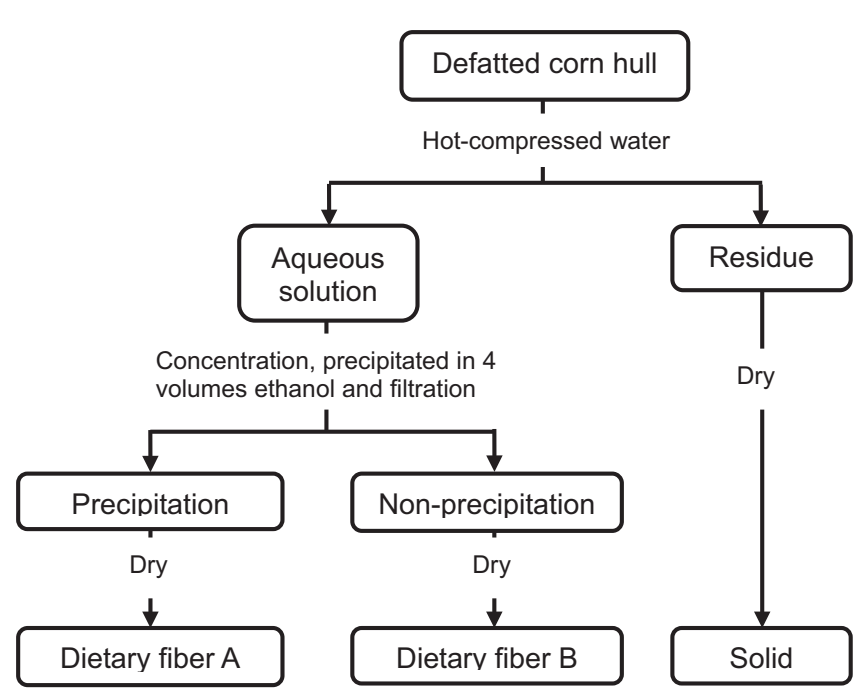

FIGURE 1. Procedure for separation of dietary fiber A, dietary fiber B and solid residue from defatted corn hull by hot-compressed water. 
for $2.5 \mathrm{~h}$ at $105^{\circ} \mathrm{C}$ ). The hydrolysate was subjected to acid hydrolysis to assure all the oligomers would be broken to monomers, and could be detected as reducing sugars [Miller, 1959]. Fructose, rhamnose, arabinose, xylose, mannose, glucose, galactose, glucuronic acid and galacturonic acid were used as the monosaccharide standards. After hydrolysis, the sample was diluted 50-fold, filtered and then injected into the HPAEC system (Dionex, ICS-3000, USA) with an AS50 auto-sampler and a Carbopac PA-20 column $(4 \times$ $250 \mathrm{~mm}$, Dionex).

\section{RESULTS AND DISCUSSION}

\section{Effect of temperature on DFA, SR and DFB yields}

Reaction temperature plays an important role in the DFA, DFB and SR yields. In this paper, 110, 130, 150, 155, 160, and $180^{\circ} \mathrm{C}$ were selected to investigate the influence of the temperature on the SDF and IDF distributions. Defatted corn hull was first broken down to some fragments and the fragments were then degraded to smaller compounds by dehydration, dehydrogenation, deoxygenation and decarboxylation [Nielsen, 2010; Miller, 1959]. These compounds, once produced, would be rearranged through polymerization, condensation and cyclization under inert atmosphere and hydrogen donor solvent, leading to the formation of new compounds (such as SR, DFA and DFB). The dependence of the product yield of hydrothermal treatment of corn hull on the temperature is shown in Figure 2 when the other two factors (corn hull to water ratio and time) were fixed at 1: 20 and $40 \mathrm{~min}$, respectively. The yield of SR decreased with temperature increasing from 110 to $160^{\circ} \mathrm{C}$, and kept invariant with final temperature increasing from 160 to $180^{\circ} \mathrm{C}$. Due to the thermal degradation, the content of SR in the solid decreased. It was deduced that the macromolecules such as cellulose, hemicelluloses, lignin, and protein broke down into smaller molecules during the procedure treated by hot compressed water [Yuliansyah et al., 2010]. This result agreed with the report obtained from woody biomass, it was found that the solid residue charac-

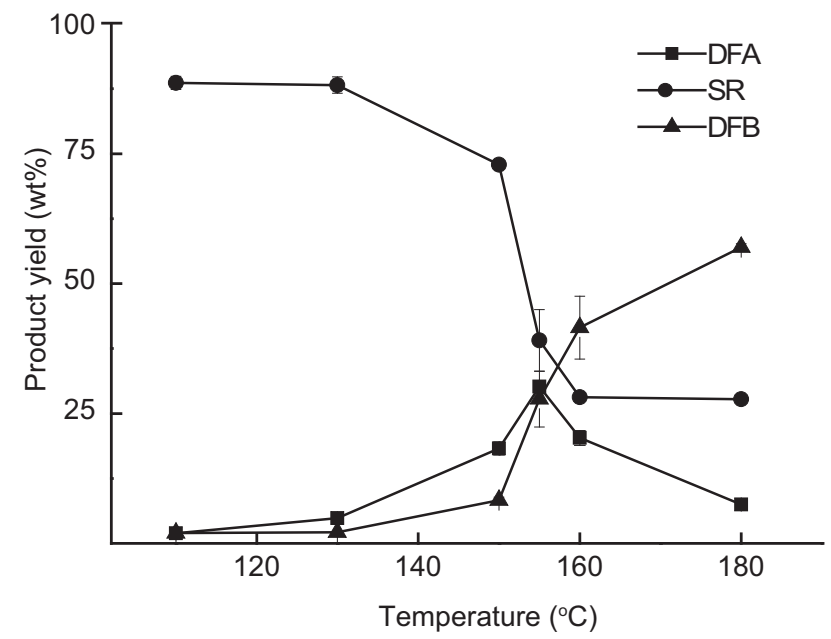

FIGURE 2. Effect of extraction temperature $\left(110-180^{\circ} \mathrm{C}\right)$ on dietary fiber A (DFA), solid residue (SR) and dietary fiber B (DFB) yields at a corn hull to water ratio of $1: 20 \mathrm{~g} / \mathrm{mL}$ for $40 \mathrm{~min}$. teristics obtained in HCW changed drastically depending on the reaction temperature [Kobayashi et al., 2009].

The DFA yield increased with increasing temperature (the maximum yield of $30.2 \%$ was observed at $155^{\circ} \mathrm{C}$ ), and then slightly decreased when the temperature was over $155^{\circ} \mathrm{C}$. The increase in yield with temperature was due to increase in water solvating power at higher temperature. The result demonstrated that temperature had a remarkable influence on DFA yield, and the excessively high temperature promoted the decomposition of the DFA into degraded products. The similar result was also confirmed by Ueno et al. [2008]. In that study, the amount of total sugar was dramatically increased with increasing temperature, and the pectin yield reached as high as $80 \%$ when the temperature reached $160^{\circ} \mathrm{C}$, which indicated that monosaccharide started to separate from the cell wall in the range of temperature. Temperature was the main parameter affecting the physicochemical properties (viscosity, dielectric constant, and surface tension are reduced at higher temperature) of water and the extracted compounds, and it had a great influence on the extraction yield and efficiency in HCW. Enhancement of the extraction efficiency might be related to the increased vapor pressures and accelerated thermal desorption of the compounds from the sample matrix [Teo et al., 2010]. The bran extract prepared at 50 to $100^{\circ} \mathrm{C}$ exhibited only the water-soluble phase at the high water activities. However, those prepared at 150 to $180^{\circ} \mathrm{C}$ exhibited the two different phases of water-soluble and insoluble materials. Over the whole range of temperature, the DFB yield increased continuously with increasing temperature. At the low and moderate temperatures of 110 to $150^{\circ} \mathrm{C}$, the yields of DFB were $2.0 \%$ to $8.3 \%$. However, as the temperature increased from 155 to $180^{\circ} \mathrm{C}$, the yield of DFB reached the maximum $(56.9 \%)$. In general, the reason was the secondary decomposition of DFA at high temperature, which led to the formation of DFB product. The solubility increase of the soluble substances at high treatment temperature could be attributed to disruption of the bran hemicelluloses during the process of hot-compressed water treatment and the subsequent release of the soluble substances from the cell wall. In addition, the sharp increase in the ethanol-precipitated fraction at $155^{\circ} \mathrm{C}$ would be explained by the significant decomposition of the cell wall resulting from the severe heat treatment, which promoted the solubilization of the decomposition products. Thus, it can be presumed that $155^{\circ} \mathrm{C}$ would be an effective extraction temperature for the DFA fraction in HCW. A similar trend was observed in our previous study on the extraction of polysaccharides from soy hulls [Liu et al., 2016]. In that study, the effective extraction temperature of the soluble dietary fiber was obtained at $160^{\circ} \mathrm{C}$, and the reason was deduced from the difference between two materials.

\section{Effect of time on DFA, SR and DFB yields}

Duration of treatment might define the composition of products and overall conversion of corn hull. Figure 3 shows the effect of treatment time at $130,140,150^{\circ} \mathrm{C}$ on DFA, DFB, and SR yields during hydrothermal treatment of corn hull. At 130 and $140^{\circ} \mathrm{C}$, the DFA yields increased with increasing treatment time from 10 to $150 \mathrm{~min}$ (Figure 3A). However, longer treatment time at higher temperature re- 
sulted in a lower DFA yield. For example, at the temperature of $150^{\circ} \mathrm{C}$, the DFA yield reached a maximum of $33.0 \%$ at $60 \mathrm{~min}$ and decreased to $24.2 \%$ as treatment time increased from 80 to $150 \mathrm{~min}$. The yield of DFA decreased as the treatment time was prolonged at higher temperature, owing to the conversion of DFA to DFB. These results suggest that a relative short heating time (around $60 \mathrm{~min}$ ) at $150^{\circ} \mathrm{C}$ is more beneficial for availability of the valuable substances in the corn hull, but prolonged heating results in adverse effects on those substances. As shown in Figure 3B, the yields
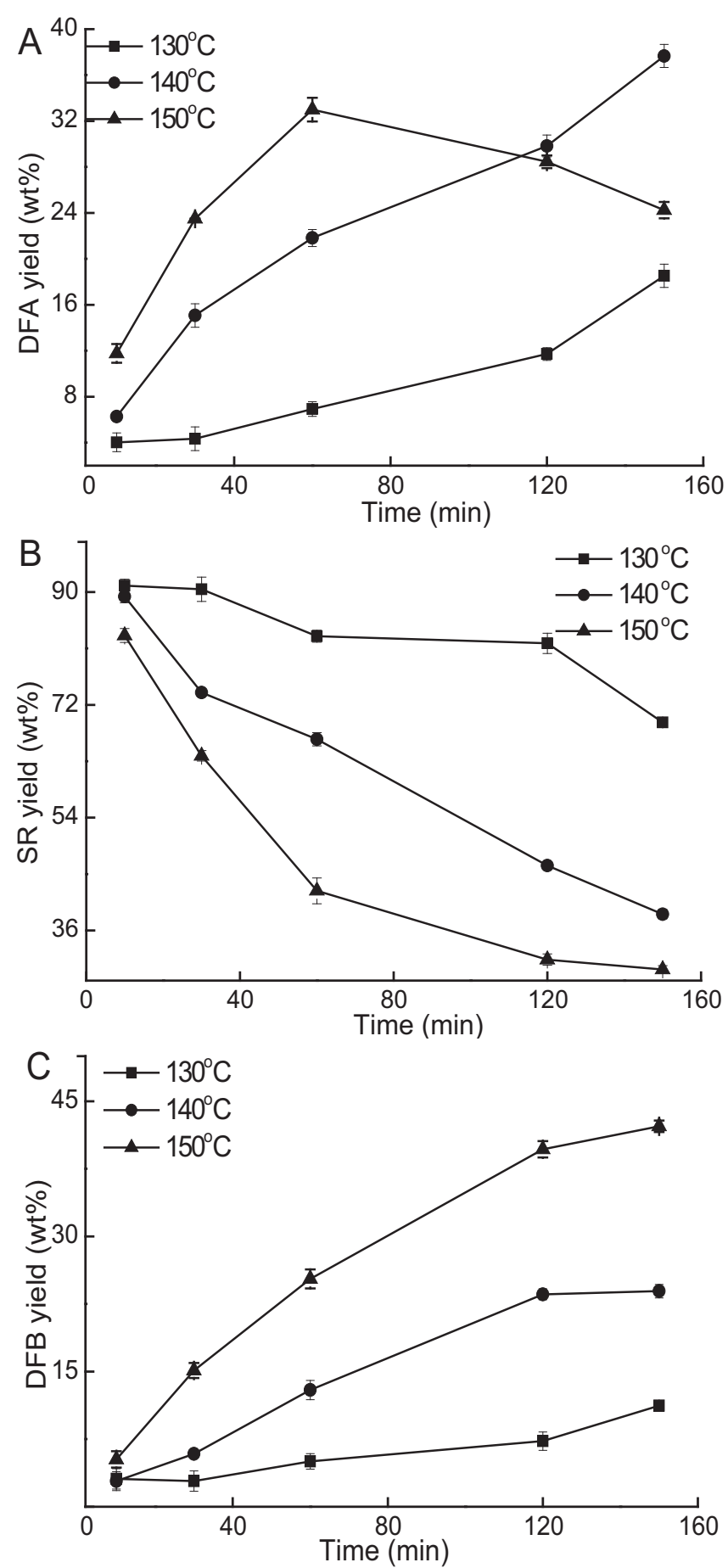

FIGURE 3. Effect of treatment time (10-150 min) on dietary fiber A (DFA), solid residue (SR) and dietary fiber B (DFB) yields at 130, 140, and $150^{\circ} \mathrm{C}$ and a corn hull to water ratio of $1: 20 \mathrm{~g} / \mathrm{mL}$. of SR decreased with increasing time ranging from 10 to 150 min for all temperature experiments. The SR yield decreased for longer hydrothermal treatment time, which led to thermal degradation of the corn hull. Meanwhile, due to the chemical bonds in the corn hull were broken, the largechain compounds such as cellulose, hemicelluloses and crude protein were broken down into smaller and simpler molecules. Clearly, the yields of DFB increased continuously with increasing treatment time in the whole range of the treatments at all temperature conditions.

Since higher temperature and longer treatment time resulted in a lower DFA yield, moderate temperature and short treatment time were preferred. Operating the reactor system at moderate and short time was favorable because the DFA yield would be high, and heat loss per unit mass for producing the DFA could be significantly low. These results indicated that the process was more energy efficient.

\section{Effect of corn hull to water ratio on DFA, SR and DFB yields}

The major functions of water during hydrothermal treatment of corn hull are decomposing the raw material and providing active hydrogen. Since various amounts of water provided for various headspace volumes and reaction pressures, they had an effect on the rates of hydrolysis. Figure 4 shows the effect of corn hull to water ratio on the product yields. Obviously, the corn hull to water ratio was an important factor on the hydrothermal treatment of corn hull. As the ratio of corn hull to water decreased from 1:8 to $1: 20 \mathrm{~g} / \mathrm{mL}$, the SR yield decreased from $62.0 \%$ to $53.0 \%$, and then increased to $54.8 \%$ when the ratio of corn hull to water further decreased to $1: 50$. This showed that the water had an important effect on the conversion rate of hydrothermal treatment process. In this study, the objection was focused on the DFA yield, since it was the product fraction of primary interest. It was clear from Figure 4 that the yields of DFA and DFB increased with decreasing the ratio of corn hull to water at first, and then decreased further decreasing the ratio of corn hull to water. The consumption of water directly influenced the cost and energy consumption of subcritical water treatment. For practical

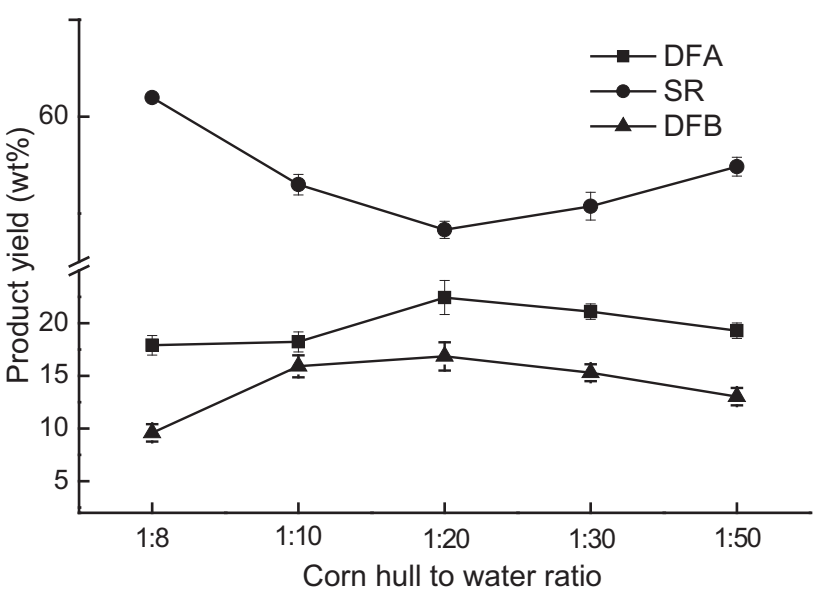

FIGURE 4. Effect of corn hull to water ratio $(1: 8-1: 50 \mathrm{~g} / \mathrm{mL})$ on dietary fiber A (DFA), solid residue (SR) and dietary fiber B (DFB) yields at $140^{\circ} \mathrm{C}$ for $40 \mathrm{~min}$. 
use, how to choose an optimum water amount for hydrothermal treatment process was very crucial and the treatment conditions should be further optimized [Matsunaga et al., 2008].

\section{Protein, starch and total sugar analysis of DFA}

The products from each hot-compressed water extraction experiment included gases, water-soluble products, and solid product insoluble in water (solid residue). The water-soluble products were also divided into ethanol-insoluble fraction (DFA) and ethanol-soluble fraction (DFB) by washing with $70 \%$ ethanol. In this study, the objection was focused on the DFA yields, since they were the product fractions of primary interest.

Figure 5 shows that DFA extracted from defatted corn hull by $\mathrm{HCW}$ at 130,150 and $180^{\circ} \mathrm{C}$ had high contents of total sugar (over $86.9 \%$ ), low protein $(2.9 \%-9.2 \%)$, and starch (9.0\%-15.0\%) contents.

Decrease in the carbohydrate content at the treatment temperatures over $200^{\circ} \mathrm{C}$ would be ascribed to the hydrolysis of poly- or oligosaccharide and degradation of constituent monosaccharides due to high ion product of water at high temperatures [Sasaki et al., 1998; Wiboonsirikul et al., 2007a]. The DFA fractions obtained below $200^{\circ} \mathrm{C}$ showed higher total sugar contents, and most of them belonged to polysaccharides. Polysaccharides were essential biomacromolecules and widely existed in the plants, microorganisms, algae, and animals. Some polysaccharides isolated from natural sources showed various biological activities such as antidiabetic, antitumor, immunomodulatory, and anti-inflammatory effects [Huang et al., 2012; Jiang et al., 2011; Kang et al., 2011; RenJie, 2008], and they were strongly affected by their chemical structures and chain conformations [Yang \& Zhang, 2009]. Because the presence of polysaccharides, the soluble dietary fiber from defatted corn hull might be a kind of good resource which could be applied to the medicine and food field. In the following research, the specific structure and the various biological activities (antidiabetic, antitumor, immunomodulatory and so on) of DFA, SR and DFB would be investigated. The waste materials of corn hulls would be taken full advantage and produce higher added-value.

Exposure of the corn hull to high temperature would lead the formation of browning reaction products [Wiboonsirikul et al., 2007a]. Due to the extract of corn hulls contained proteins and carbohydrates, the browning reaction was one of dominant reactions occurring during the $\mathrm{HCW}$ treatment. Furfural is a well-known intermediate product formed during the early stage of the non-enzymatic browning reaction and used as an indicator for the progress of either the Maillard browning reaction or caramelization [Cerrutti et al., 1985; Tsai et al., 2005]. The furfural content increased with increasing temperature. The DFA color was deeper over temperature when other conditions were the same. The discoloration temperature was $150^{\circ} \mathrm{C}$ and the result was consistent with findings reported by Wiboonsirikul et al. [2007b]. These results indicated that the browning reaction significantly occurred when the bran was treated at over $150^{\circ} \mathrm{C}$.

Alkaline extraction and hot water extraction were the traditional extraction methods, which were low efficiency, timeconsuming and sometimes they could produce toxic wastes

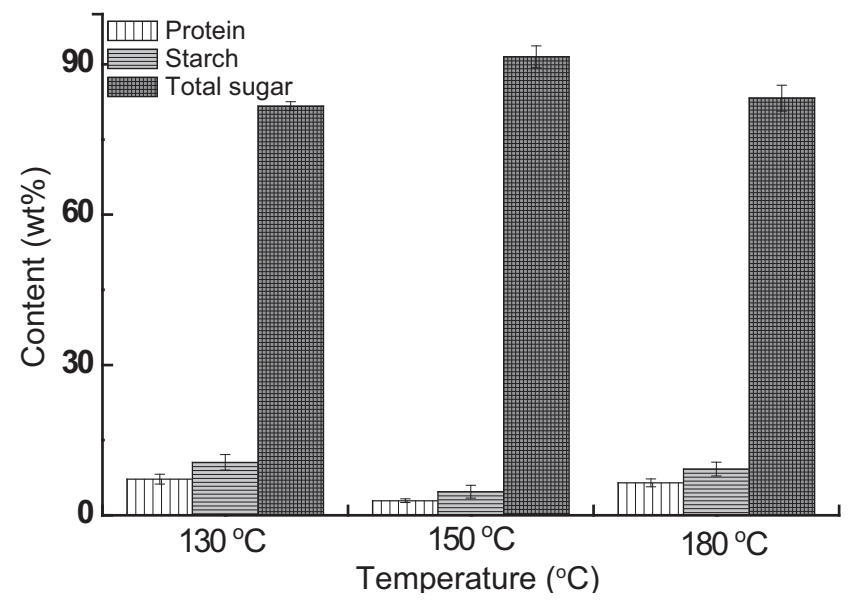

FIGURE 5. Contents of protein, starch, and total sugar of dietary fiber A at 130,150 , and $180^{\circ} \mathrm{C}$ (corn hull to water ratio, 1: 20 and time, $40 \mathrm{~min}$ ).

during the process. However, the hot-compressed water was environment-friendly because it did not use organic solvent and alleviated the problems.

\section{FT-IR Characterization}

FT-IR is a powerful technique for the identification of characteristic organic groups in the polysaccharides. Effective use of infrared spectroscopy in investigating structure and conformation of carbohydrates requires an understanding of the structural and vibrational origin of the observed frequencies. For FT-IR analysis, five frequency regions could be distinguished (4000-650 $\left.\mathrm{cm}^{-1}\right)$ : (1) $3600-2800 \mathrm{~cm}^{-1}$ for region of O-H and C-H stretching vibrations; (2) 1500-1200 $\mathrm{cm}^{-1}$ for region of local symmetry; (3) $1200-950 \mathrm{~cm}^{-1}$ for region of C-O stretching vibration; (4) $950-700 \mathrm{~cm}^{-1}$ for fingerprint or anomeric region; and (5) $700 \mathrm{~cm}^{-1}$ below for skeletal region [Mathlouthi et al., 1986].

As shown in Figure 6A, the FT-IR spectra of DFA at 130, 150 and $180^{\circ} \mathrm{C}$ (corn hull to water ratio, 1: 20 and time, $40 \mathrm{~min}$ ) display a broad and strong peak at $3398 \mathrm{~cm}^{-1}$, respectively, which was attributed to the hydroxyl groups stretching vibration. The bands in the region of $2925 \mathrm{~cm}^{-1}$ were the characteristic of $\mathrm{C}-\mathrm{H}$ stretching vibration. The weak absorption of $2367 \mathrm{~cm}^{-1}$ also indicated the existence of aliphatic $\mathrm{C}-\mathrm{H}$ bonds in EP at 130,150 and $180^{\circ} \mathrm{C}$. The bands at around 1730 and $1632 \mathrm{~cm}^{-1}$ represented the ester carbonyl groups $(\mathrm{C}=\mathrm{O})$ and carboxylate (COO-) stretching [Gnanasambandam \& Proctor, 2000], respectively, indicated that there were esterified and free carboxyl groups present in the 130, 150, and $180^{\circ} \mathrm{C}$ DFAs. In the carbonyl stretching region, the bands between 1659 and $1573 \mathrm{~cm}^{-1}$ were due to the absorbed water [Sun \& Tomkinson, 2002], and starch presented infrared bands in the $1200-800 \mathrm{~cm}^{-1}$ spectral region.

The bands at $1160-30 \mathrm{~cm}^{-1}$ were dominated by the glycosidic linkage (C-O-C) from xylan, xyloglucan and glucan. The presence of xylan-rich polysaccharide in the DFA was evidenced also by its FT-IR spectral pattern in the $800-1700 \mathrm{~cm}^{-1}$ region [Sun \& Tomkinson, 2002]. The FT-IR spectral patterns of SR and DFB were similar to the DFA spectrum (Figure 6B, C). There were no notable differences for the FT-IR spectra among DFA, SR, and DFB at different temperatures. 


\section{Monosaccharide composition analysis of DFA, DFB and SR}

Arabinose, xylose, glucose and fructose are four kinds of typical monosaccharides involved in life. Besides, arabinose and xylose are capable of improving human immunity due to their benefits on bifidobacterium growth. Moreover, monosaccharides have a great effect on the taste and smell of plant products, such as tea and tobacco [Wei et al., 2010; Clarke et al., 2006; Zhang et al., 2014], so the detection of monosaccharides becomes very important. The sugar compositions of the DFA and DFB fractions extracted from defatted corn hull by $\mathrm{HCW}$ at 130,150 , and $180^{\circ} \mathrm{C}$ (corn hull to water ratio, 1: 20 and time, $40 \mathrm{~min}$ ) were identified
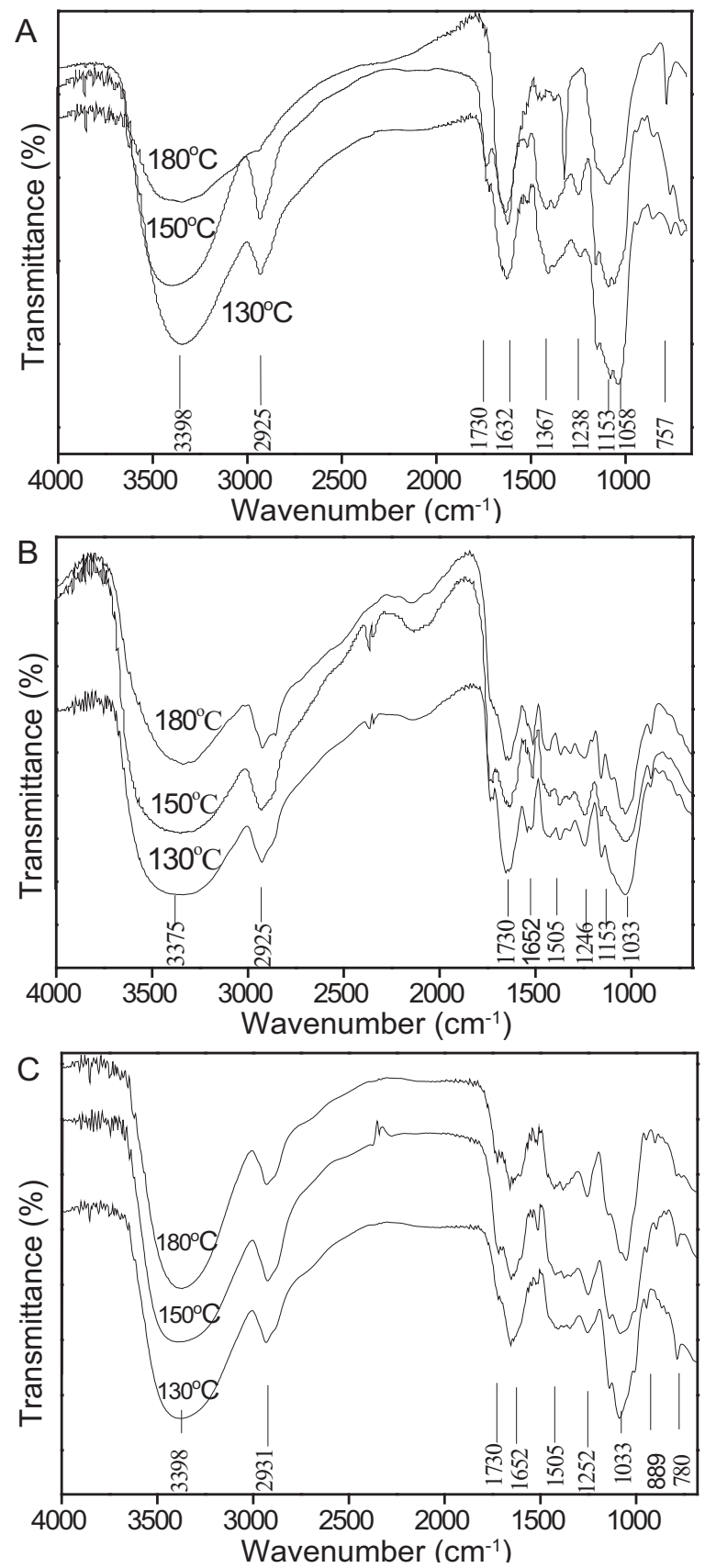

FIGURE 6. FT-IR spectra of dietary fiber A (A), solid residue (B) and dietary fiber $\mathrm{B}(\mathrm{C})$ at 130,150 , and $180^{\circ} \mathrm{C}$ (corn hull to water ratio, 1: 20 and time, $40 \mathrm{~min})$.
TABLE 1. Compositions of dietary fiber A (DFA), dietary fiber B (DFB) and solid residue (SR) polysaccharides from defatted corn hull at 130, 150 , and $180^{\circ} \mathrm{C}$ (\% dry weight).

\begin{tabular}{l|c|c|c|c|c}
\hline Fraction & $\begin{array}{c}\text { Arabinose } \\
(\%)\end{array}$ & $\begin{array}{c}\text { Galactose } \\
(\%)\end{array}$ & $\begin{array}{c}\text { Glucose } \\
(\%)\end{array}$ & $\begin{array}{c}\text { Xylose } \\
(\%)\end{array}$ & $\begin{array}{c}\text { Uronic } \\
\text { acid } \\
(\%)\end{array}$ \\
\hline DFA-130 ${ }^{\circ} \mathrm{C}$ & $15.4 \pm 0.3$ & $2.8 \pm 0.6$ & $73.1 \pm 0.2$ & $8.1 \pm 0.4$ & $0.5 \pm 0.2$ \\
DFA-150 ${ }^{\circ} \mathrm{C}$ & $16.9 \pm 0.2$ & $2.8 \pm 1.1$ & $56.0 \pm 0.7$ & $23.2 \pm 0.3$ & $1.2 \pm 0.3$ \\
DFA- $180{ }^{\circ} \mathrm{C}$ & $3.8 \pm 0.6$ & $3.0 \pm 0.1$ & $65.0 \pm 0.6$ & $25.6 \pm 1.2$ & $2.7 \pm 0.1$ \\
DFB-130 ${ }^{\circ} \mathrm{C}$ & $38.0 \pm 0.5$ & $6.1 \pm 0.7$ & $48.6 \pm 0.6$ & $7.3 \pm 0.1$ & $0.0 \pm 1.1$ \\
DFB-150 ${ }^{\circ} \mathrm{C}$ & $65.6 \pm 0.1$ & $6.8 \pm 0.2$ & $7.1 \pm 0.4$ & $19.2 \pm 1.3$ & $1.3 \pm 0.5$ \\
DFB-180 ${ }^{\circ} \mathrm{C}$ & $10.2 \pm 0.4$ & $37.7 \pm 0.3$ & $0.9 \pm 0.2$ & $51.1 \pm 0.5$ & $0.0 \pm 0.8$ \\
SR-130 ${ }^{\circ} \mathrm{C}$ & $27.9 \pm 1.4$ & $7.1 \pm 0.2$ & $12.6 \pm 0.7$ & $49.8 \pm 0.4$ & $2.6 \pm 0.6$ \\
SR-150 ${ }^{\circ} \mathrm{C}$ & $24.9 \pm 0.4$ & $8.0 \pm 0.2$ & $9.6 \pm 0.8$ & $57.0 \pm 0.5$ & $0.6 \pm 1.3$ \\
SR-180 ${ }^{\circ} \mathrm{C}$ & $4.9 \pm 0.3$ & $5.7 \pm 1.1$ & $49.7 \pm 0.5$ & $39.8 \pm 0.2$ & $0.0 \pm 0.6$ \\
\hline
\end{tabular}

and qualified. The results (Table 1) were consistent with those reported by Luc Saulnier et al. [1995b], which indicated the major sugar constituents of polysaccharides obtained from defatted corn hull were arabinose, galactose, glucose, xylose, and uronic acid. However, there were no significant differences among them. The data showed that DFA and DFB were both composed of arabinose, galactose, glucose, xylose, and uronic acid. The predominant sugar of DFA extracted from hydrothermal treatment of defatted corn hull at various temperatures was glucose, which accounted for $56.0-73.0 \%$ (monosaccharide/material, \% dry weight) followed by xylose $(8.1-25.6 \%)$ and arabinose $(3.8-16.9 \%)$. And also, the galactose and uronic acid contents were less, and they accounted for $2.8-3.0 \%$ and $0.5-2.7 \%$, respectively. There were no significant differences among DFA polysaccharide compositions and monosaccharide contents at various temperatures. Clearly, treatment temperature had an important effect on the monosaccharide contents in the DFB fractions compared with DFA fractions. The galactose and xylose contents increased from $6.1 \%$ at $110^{\circ} \mathrm{C}$ to $37.7 \%$ at $180^{\circ} \mathrm{C}, 7.3 \%$ at $110^{\circ} \mathrm{C}$ to $51.1 \%$ at $180^{\circ} \mathrm{C}$, respectively. The result demonstrated that higher HCW temperature favored the production of galactose and xylose with higher percentages in DFB fractions. On the contrary, the content of glucose decreased from $48.6 \%$ to $0.9 \%$ as the temperature increased. The result indicated that lower HCW temperature favored glucose production. Additionally, the arabinose content was relatively high (10.2\%$65.6 \%$ ), while the low content of uronic acid was $0.0 \%-1.3 \%$.

The SR polysaccharide compositions were similar to those of DFA and DFB in Table 1, the highest content was found for xylose (39.8\%-57.0\%) in the monosaccharide compositions of SR fractions. The arabinose content decreased from $27.9 \%$ to $4.9 \%$ as HCW temperature increased. There was no obvious regular pattern in the contents of the remaining monosaccharides (galactose, glucose and uronic acid). According to the SR polysaccharide compositions, the SR was also one of resources to produce xylose, and that demonstrated the polysaccharide was not extracted completely by HCW. This method could provide reference for other 
studies on polysaccharides possibly obtained from the varied sources or growth environments of the corn hull samples. And also, the researchers could choose the different portions according to their demands.

\section{CONCLUSIONS}

Subcritical water in the temperature region of $110-180^{\circ} \mathrm{C}$ offered opportunities both as a benign solvent and a selfneutralizing catalyst. Here, water acted as both a reactant and the reaction medium. Water led to hydrolysis reactions and rapidly degraded the polymeric structure of corn hull to water-soluble products. The present work showed that the method of HCW extraction was the effective method to isolate soluble DFA from corn hull. The DFA yield reached a maximum $(33.0 \%)$ at $150^{\circ} \mathrm{C}$ for $60 \mathrm{~min}$. The predominant monosaccharide in DFA extracted at various temperatures was glucose, the content of which ranged from $56.0 \%$ to $73.1 \%$ of the total neutral sugars. There were no significant differences among polysaccharide compositions, monosaccharide contents and the FT-IR spectra of DFA, SR and DFB at various temperatures. The DFA, SR and DFB could be prepared for the application in the food industry using an environment-friendly and safe extractant. These products should be economical as they were isolated from the abundant and inexpensive by-products of the corn wet milling and dry milling processes.

\section{RESEARCH FUNDING}

This research was supported by Province Key Laboratory of Transformation and Utilization of Cereal Resource (24400035), a Postdoctoral Research Sponsorship in Henan Province (2015024) and a China Postdoctoral Science Foundation Grant (2016M592313).

\section{CONFLICT OF INTERESTS}

Authors declare no conflict of interest.

\section{REFERENCES}

1. AOAC. Official Methods of Analysis of AOAC International. $18^{\text {th }}$ Edition. Editor Horowitz. W. Latimer. G.W. AOAC International, 2005, Maryland. USA.

2. Carr A.G., Branch A., Mammucari R., Foster N.R., The solubility and solubility modelling of budesonide in pure and modified subcritical water solutions. J. Supercrit. Fluid., 2010, 55, 37-42.

3. Cerrutti P., Resnik S., Seldes A., Fontan C.F., Kinetics of deteriorative reactions in model food systems of high water activity: glucose loss, 5-hydroxymethylfurfural accumulation and fluorescence. J. Food Sci., 1985, 50, 627-630.

4. Chanliaud E., Saulnier L., Thibault J.F., Alkaline extraction and characterisation of heteroxylans from maize bran. J. Cereal Sci., 1995, 21, 195-203.

5. Clarke M.B., Bezabeh D.Z., Howard C.T., Determination of carbohydrates in tobacco products by liquid chromatography-mass spectrometry/mass spectrometry: a comparison with ion chromatography. J. Agric. Food Chem., 2006, 54, 1975-1981.
6. Dhingra D., Michael M., Rajput H., Patil R., Dietary fibre in foods: a review J. Food Sci. Tech., 2012, 49, 255-266.

7. Foschia M., Peressini D., Sensidoni A., Brennan C.S., The effects of dietary fibre addition on the quality of common cereal products. J. Cereal Sci., 2013, 58, 216-227.

8. Gáspár M., Juhász T., Szengyel Z., Réczey K., Fractionation and utilisation of corn fibre carbohydrates. Process Biochem., 2005, 40, 1183-1188.

9. Gáspár M., Kálmán G., Réczey K., Corn fiber as a raw material for hemicellulose and ethanol production. Process Biochem., 2007, 42, 1135-1139.

10. Gnanasambandam R., Proctor A., Determination of pectin degree of esterification by diffuse reflectance Fourier transform infrared spectroscopy. Food Chem., 2000, 68, 327-332.

11. Huang Y.L., Chow C.J., Tsai Y.H., Composition, characteristics, and in-vitro physiological effects of the water-soluble polysaccharides from Cassia seed. Food Chem., 2012, 134, 1967-1972.

12. Jiang C., Wang M., Liu J., Gan D., Zeng X., Extraction, preliminary characterization, antioxidant and anticancer activities in vitro of polysaccharides from Cyclina sinensis. Carbohyd. Polym., 2011, 84, 851-857.

13. Kálmán G., Recseg K., Gáspár M., Réczey K., Novel approach of corn fiber utilization. Appl. Biochem. Biotech., 2006, 131, 738-750.

14. Kang S.M., Kim K.N., Lee S.H., Ahn G., Cha S.H., Kim A.D., Yang X.D., Kang M.C., Jeon Y.J., Anti-inflammatory activity of polysaccharide purified from AMG-assistant extract of Ecklonia cava in LPS-stimulated RAW 264.7 macrophages. Carbohydr. Polym., 2011, 85, 80-85.

15. Kobayashi N., Okada N., Hirakawa A., Sato T., Kobayashi J., Hatano S., Itaya Y., Mori S., Characteristics of solid residues obtained from hot-compressed-water treatment of woody biomass. Ind. Eng. Chem. Res., 2009, 48, 373-379.

16. Liu H.M., Xie X.A., Li M.F., Sun R.C., Hydrothermal liquefaction of cypress: effects of reaction conditions on 5-lump distribution and composition. J. Anal. Appl. Pyrol., 2012, 94, 177-183.

17. Liu H.M., Liu Y., Effect of different solvents on cypress liquefaction to fuels and characterization of products. BioResources, 2013, 8, 6211-6219.

18. Liu H.M., Wang F.Y., Liu Y.L., Hot-compressed water extraction of polysaccharides from soy hulls. Food Chem., 2016, 202, 1, 104-109.

19. Łozak A., Sołtyk K., Kiljan M., Fijałek Z., Ostapczuk P., Determination of selected trace elements in dietary supplements containing plant materials. Pol. J. Food Nutr. Sci., 2012, 62, 97-102.

20. Makowska A., Mildner-Szkudlarz S., Obuchowski W., Effect of brewer's spent grain addition on properties of corn extrudates with an increased dietary fibre content. Pol. J. Food Nutr. Sci., 2013, 63, 19-24.

21. Matsunaga M., Matsui H., Otsuka Y., Yamamoto S., Chemical conversion of wood by treatment in a semi-batch reactor with subcritical water. J. Supercrit. Fluid., 2008, 44, 364-369.

22. Mathlouthi M., Koenig J.L., Vibrational spectra of carbohydrates. Adv. Carbohydr. Chem. Biochem., 1986, 44, 7-89.

23. Merali Z., Collins S.R.A., Elliston A., Wilson D.R., Käsper A., Waldron K.W., Characterization of cell wall components of wheat bran following hydrothermal pretreatment and fractionation. Biotechnol. Biofulls, 2015, 8, 23. 
24. Miller G.L., Use of dinitrosalicylic acid reagent for determination of reducing sugar. Anal. Chem., 1959, 31, 426-428.

25. Nielsen S.S., Phenol-sulfuric acid method for total carbohydrates. Food Analysis Laboratory Manual, 2010, 2nd ed., Springer US, New York.

26. Peng F., Peng P., Xu F., Sun R.C., Fractional purification and bioconversion of hemicelluloses. Biotechnol. Adv., 2012, 30, 879-903.

27. RenJie L., Orthogonal test design for optimization of the extraction of polysaccharides from Phascolosoma esulenta and evaluation of its immunity activity. Carbohydr. Polym., 2008, 73, 558-563.

28. Rogalinski T., Liu K., Albrecht T., Brunner G., Hydrolysis kinetics of biopolymers in subcritical water. J. Supercrit. Fluid., 2008, 46, 335-341.

29. Sasaki M., Kabymela B., Malaluan R., Hirose S., Takeda N., Adschiri T., Arai K., Cellulose hydrolysis in subcritical and supercritical water. J. Supercrit. Fluid., 1998, 13, 261-268.

30. Saulnier L., Vigouroux J., Thibault J.F., Isolation and partial characterization of feruloylated oligosaccharides from maize bran. Carbohydr. Res., 1995a, 272, 241-253.

31. Saulnier L., Marot C., Chanliaud E., Thibault J.F., Cell wall polysaccharide interactions in maize bran. Carbohydr. Polym., 1995b, 26, 279-287.

32. Sugawara M., Benno Y., Takeuchi M., Mitsuoka T., Effect of corn fiber on fecal flora, properties of feces, $\beta$-glucuronidase, and levels of serum lipid in healthy men. Agric. Biol. Chem., 1989, 53, 2625-2630.

33. Sugawara M., Suzuki K., Endo K., Kumemura M., Takeuchi M., Mitsuoka T., Effect of the dietary supplementation of corn hemicellulose on fecal flora and bacterial enzyme activities in human adults. Agric. Biol. Chem., 1990, 54, 1683-1688.

34. Sugawara M., Benno Y., Koyasu E., Takeuchi M., Mitsuoka T., Digestion and fermentation by human intestinal bacteria of corn fiber and its hemicellulose in vitro. Agric. Biol. Chem., 1991a, 55, 565-567.

35. Sugawara M., Sato Y., Yokoyama S., Mitsuoka T., Effect of corn fiber residue supplementation on fecal properties, flora, ammonia, and bacterial enzyme activities in healthy humans. J. Nutr. Sci. Vitaminol., 1991b, 37, 109-116.

36. Sun R.C., Tomkinson J., Characterization of hemicelluloses obtained by classical and ultrasonically assisted extractions from wheat straw. Carbohydr. Polym., 2002, 50, 263-271.
37. Teo C.C., Tan S.N., Yong J.W. H., Hew C.S., Ong E.S., Pressurized hot water extraction (PHWE). J. Chromatogr. A, 2010, 1217, 2484-2494.

38. Tsai P., Delva L., Yu T., Huang Y., Dufosse L., Effect of sucrose on the anthocyanin and antioxidant capacity of mulberry extract during high temperature heating. Food Res. Int., 2005, 38, 1059-1065.

39. Ueno H., Tanaka M., Hosino M., Sasaki M., Goto M., Extraction of valuable compounds from the flavedo of Citrus junos using subcritical water. Sep. Purif. Technol., 2008, 62, 513-516.

40. Wang X., Chen Q.R., Lü X., Pectin extracted from apple pomace and citrus peel by subcritical water. Food Hydrocolloid., 2014, 38, 129-137.

41. Wei X., Chen M., Xiao J., Liu Y., Yu L., Zhang H., Wang Y., Composition and bioactivity of tea flower polysaccharides obtained by different methods. Carbohydr. Polym., 2010, 79, 418-422.

42. Wiboonsirikul J., Hata S., Tsuno T., Kimura Y., Adachi S., Production of functional substances from black rice bran by its treatment in subcritical water. LWT - Food Sci. Technol., 2007a, 40, 1732-1740.

43. Wiboonsirikul J., Kimura Y., Kadota M., Morita H., Tsuno T., Adachi S., Properties of extracts from defatted rice bran by its subcritical water treatment. J. Agric. Food Chem., 2007b, 55, 8759-8765.

44. Yadav M.P., Hicks K.B., Johnston D.B., Hotchkiss Jr. A.T., Chau H.K., Hanah K., Production of bio-based fiber gums from the waste streams resulting from the commercial processing of corn bran and oat hulls. Food Hydrocoll., 2016, 53, 125-133.

45. Yang L., Zhang L.M., Chemical structural and chain conformational characterization of some bioactive polysaccharides isolated from natural sources. Carbohydr. Polym., 2009, 76, 349-361.

46. Yuliansyah A.T., Hirajima T., Kumagai S., Sasaki K., Production of solid biofuel from agricultural wastes of the palm oil industry by hydrothermal treatment. Waste Biomass Valori., 2010, 1, 395-405.

47. Zhang Y., Li H.F., Ma Y., Jin Y., Kong G., Lin J.M., Microwave assisted extraction-solid phase extraction for high-efficient and rapid analysis of monosaccharides in plants. Talanta, 2014, 129, 404-410.

Submitted: 21 July 2016. Revised: 28 November 2016; 11 January 2017, and 13 February 2017. Accepted: 28 February 2017. Published on-line: 12 July 2017. 